\title{
Reprocessing and repairing white and brown goods - the R.U.S.Z case: an independent and non-profit business
}

\author{
Gernot Lechner $^{*}$ and Marc Reimann ${ }^{\dagger}$
}

\author{
${ }^{*}$ Correspondence: \\ gernot.lechner@uni-graz.at \\ ${ }^{\dagger}$ Equal contributors \\ Department of Production and \\ Operations Management, University \\ of Graz, Universitaetsstrasse 15/E3, \\ Graz, Austria
}

\begin{abstract}
Reprocessing of used products is a growing field, with respect to both scientific and practical approaches. In this context, we present an in-depth case study dealing with the reverse logistics processes at Repair- and Service Center R.U.S.Z, an Austrian Work Integration Social Enterprise (WISE) located in Vienna, Austria. The main business segments of R.U.S.Z are reprocessing, repairing, and servicing of (used) products and repair services. The reverse logistics activities include relevant processes like acquisition, testing and grading, and disposition/reprocessing of used goods. Based upon the case study, we present the gained insights and furthermore identify research opportunities. Our main findings are: (1) the reverse logistics activities of this non-profit-organization are equivalent compared with the profit-driven approaches used in literature; (2) the business of R.U.S.Z is not solely profit- or cost-driven but the company is based on the triple bottom line and pursues environmental and social goals, too; (3) in spite of legislation aiming at the reuse of used products, there is lack of collaboration between manufacturers and reprocessors.
\end{abstract}

Keywords: Reprocessing; Reuse; Independent remanufacturer; Case study; Social Economy - Work Integration Social Enterprise

\section{Background}

"Mr. Eisenriegler, you will understand that it is not in our interest to help establish a competitor in the market sector of low-priced products."

This statement made by a representative of a large retailer for electric and electronic products to Sepp Eisenriegler, the head of Repair- and Service Center R.U.S.Z (Reparaturund Servicezentrum R.U.S.Z), represents the general attitude of manufacturers and retailers towards reused products not only in Austria. Another often mentioned aspect is the fear of negative brand image effects induced by remanufactured or refurbished goods offered on secondary markets. Not surprisingly such reservations are reflected in an extremely low reuse rate of full products ranging from around $1 \%$ for white goods to $1.34 \%$ for consumer electronics in Austria in 2013 [1].

Reuse organizations like R.U.S.Z suffer from such low rates, despite the fact that Austria has agreed to implement the 'Waste Electrical and Electronic Equipment Directive' (WEEE) directive at national level. The collection targets for used electrical or electronic (EE) products are currently $4 \mathrm{~kg}$ per person and year until the end of $2015,45 \%$ of sold

(C) 2015 Lechner and Reimann. This Open Access This article is distributed under the terms of the Creative Commons Attribution 4.0 International License (http://creativecommons.org/licenses/by/4.0/), which permits unrestricted use, distribution, and reproduction in any medium, provided you give appropriate credit to the original author(s) and the source, provide a link to the Creative Commons license, and indicate if changes were made. 
EE products (in terms of average weight) until the end of 2018 and at least $85 \%$ (in terms of product mass) starting in 2019. The corresponding national law [2] specifies that any seller (manufacturer or retailer) needs to accept used EE products on a 1:1 basis when selling a new unit. Alternatively, in mail-order or e-retailing context the seller needs to specify at least two local collection points where used products can be returned. In Austria, there are a total of about 2000 collection points which potentially prepare and forward reusable products to reprocessors. The collection system is not centralized, rather European initiatives like the ERP (European Recycling Platform, see http://erp-recycling. org/), covering manufacturers like Braun, Electrolux, HP and Sony, or the EARN (European Advanced Recycling Network, http://www.earn-service.eu/) initiated by electronics recycling companies, coexist with national consortia and networks like ElectroRecycling Austria GmbH or Umweltforum Haushalt [3].

The problems associated with the implementation of these laws are manifold. First, the decentralized nature of and discretionary participation of manufacturers and retailers in these collection systems restrict the access of reuse companies to certain types of EE used products. Second, the WEEE guideline and the associated Austrian laws, while explicitly mentioning the priority of reuse over recycling, specify a joint target for reuse and recycling. This essentially justifies any action supporting the initial statement presented at the beginning of this section, regardless of any economic or environmental benefits of reuse. Third, the law specifies that the choice of the reuse option is contingent on the technical state of an item and consequently the economic feasibility of reuse and its environmental meaningfulness [2]. Here the way collection and initial processing are performed is currently not targeted at reuse. Many of the used units will enter a shredder and only the remaining fractions are commercially utilized through mostly material recycling [4]. This destroys the economic feasibility of reuse in many cases.

Some of the above mentioned problems, as well as others, have been recognized by Austrian legislators and changes have been brought into use, or are about to be introduced. These include the restriction of illegal exports of used EE products, an improved access of reuse companies to used products, thereby increasing the anticipated share of reused products, as well as the specification of treatment standards along the reverse logistics chain to enable reuse [2].

Yet, while these changes may increase the feasibility of reuse, the economic benefit still needs to be established. For example, in [5], based on empirical data and interviews with company executives in Austria, the logistics cost associated with a system preserving the reusability of used units were estimated to exceed the cost of the - above mentioned current system by about 50-100 \%. These extra cost may not be covered by the revenues associated with sales of reused products. In fact, in Austria a significant fraction of reuse activities is currently carried out by Work Integration Social Enterprises (WISE), which are not primarily profit oriented.

One of these companies is R.U.S.Z, which is the subject of this case study. In light of the above mentioned initiative to increase reuse as well as profitability issues associated with reuse, we were interested in shedding light into the main characteristics of R.U.S.Z. The following guiding research questions were formulated and guided our research:

- What are the main characteristics and decisions of the processes at R.U.S.Z and how do they interact? 
- What are the main drivers of business at R.U.S.Z? Which factors affect the decision-making at R.U.S.Z, and how does the company cope with these influences?

- What are the unique properties of a non-profit organization dealing with reverse logistics, if there are any? How are the reverse processes organized at an NPO/SCC? How does such a firm differ from conventional profit-oriented business?

The remainder of the paper is organized as follows: in Section 'Case description' we introduce company R.U.S.Z and present an overview of the organizational structure, goals, economic and environmental issues and the company's reverse logistics. In addition we describe the applied methodology used in this study. The observations related to reprocessing of white goods and analyses of business data are detailed in Section 'Discussion and evaluation. This section also contains a comparison of our findings with current scientific literature. Finally, conclusions are drawn in Section 'Conclusions'. Based on the insights gained from the case study we raise questions in order to indicate potential fields of research.

\section{Case description}

R.U.S.Z is a Work Integration Social Enterprise focusing on reprocessing, repairing, and servicing of used products. Founded in 1998, the company pursues goals in economical, ecological, as well as social directions. Particularly, the objectives include cost recovery, reprocessing/repairing of about 8,000 used products/year, reduction of problematic waste due to prolongation of product usage phases, and reintegration of permanently unemployed persons. ${ }^{1}$

\section{Organizational structure of R.U.S.Z}

Since the foundation of R.U.S.Z in 1998, the focus is on employment of long-term unemployed people. Currently, 21 people work for the company, whereof two persons focus on strategic activities like long-term projects and calculations. Fifteen workers are assigned to three departments: nine workers are responsible for white goods, five persons focus on consumer electronics/brown goods, and one cares about reconditioning of computers. All of these workers are responsible for any of the activities which occur within a department, e.g., remanufacturing, spare parts recovery, and disposal of used products. Besides the workers, two apprentices are trained, and one person is solely responsible for the used-goods receiving. Another two part-time employees as well as Sepp Eisenriegler, the general manager of R.U.S.Z, are assigned to an overhead cost center.

From 1998 to 2007 hundreds of long-term unemployed people were reintegrated, they did a 12-month on-the-job training funded by the Public Employment Service Austria. Since the beginning of 2008, R.U.S.Z has turned to be a private non-profit company. However, still long-term unemployed people are trained. As the costs for this are not covered by public authorities in terms of subsidies, R.U.S.Z has developed a specific Corporate Social Responsibility-concept: private profit-oriented companies take over the sponsorship for the on-the-job trainings. The productive efficiency of a new worker is estimated at 50-70 \%, and the sponsorship covers the costs to cope with this reduced efficiency. On average, the worker achieves the full potential after a half year on-the-job training. 


\section{Goals of R.U.S.Z}

Contrary to many companies engaged in the reprocessing business, R.U.S.Z is not profitoriented but organized as a non-profit organization (NPO). As it is postulated in the common definition of social economy, ecological and social goals play a major role for decision-making at R.U.S.Z, next to economic objectives [8].

Although R.U.S.Z does not actively pursue the objective to maximize profits, decision - making and the company strategies must ensure financial sustainability to keep business running in the future. This is related to the fact that R.U.S.Z is self-feeding; public support is solely granted under strict conditions for the reintegration of long-term unemployed people. Therefore, the main economical objective is to earn sufficient to cover all types of costs (investments, staff, etc.). Due to the fact that R.U.S.Z is a comparatively small company, it is limited in terms of budget and investment capital. Naturally, these limitations cause that the capacities are restricted. However, from R.U.S.Z' point of view, limited reprocessing capacities are also part of the business strategy to avoid the risk of overwhelming (and subsequently, costly) resources. According to R.U.S.Z, this is one of the key factors for a sustainable business, as it helps to cope with the risk of potential supply or demand shortages due to low fixed costs.

R.U.S.Z also considers ecological and social objectives. Remanufacturing and refurbishing of used items and the subsequent reuse result in extended product usage phases. Consequently, less virgin resources are consumed, and at the same time, waste is reduced. Additionally, an optional upgrading process significantly reduces the energy consumption of washing machines. Therefore, as an ecological goal, R.U.S.Z wants to provide consumers as many reprocessed used products as possible to minimize environmental impact. Another aspect concerns consumer education: next to convincing people to repair broken products instead of throwing them away, buying of high-quality durable goods is promoted.

Regarding the social responsibility, R.U.S.Z wants to provide socially disadvantaged people with energy-efficient durable goods at reasonable prices; offering these energyefficient second-life products should substitute sales of throwaway products. Therefore, the socially disadvantaged people get a discount of $20 \%$ on all services and products offered by R.U.S.Z. Besides this goal, the main related social objective is to solely employ long-term unemployed people: R.U.S.Z provides regular work to reintegrate them in the working world. Consequently, the unemployed people get practical experience. The goal is to place all of these people in open-ended jobs, both at R.U.S.Z and other companies. All in all, 400 long-term unemployed people were employed and trained, whereof 300 people were placed in open-ended jobs.

To give a résumé, economical objectives make sure the financial continuation of the company by covering costs but not by maximizing profits, while ecological (maximize the ecological surplus, maximize the sales of reprocessed products under certain restrictions like budget, capacities, human resources) and social goals (reintegrate long-term unemployed people, on-the-job training to convey a maximum amount of knowledge) are pursued actively, too.

\section{Financial and economic implications of R.U.S.Z' activities}

The main business segments of R.U.S.Z - as indicated in Section 'Case description' - are reprocessing of used products and the repair service. The analysis of the revenues in Fig. 1 


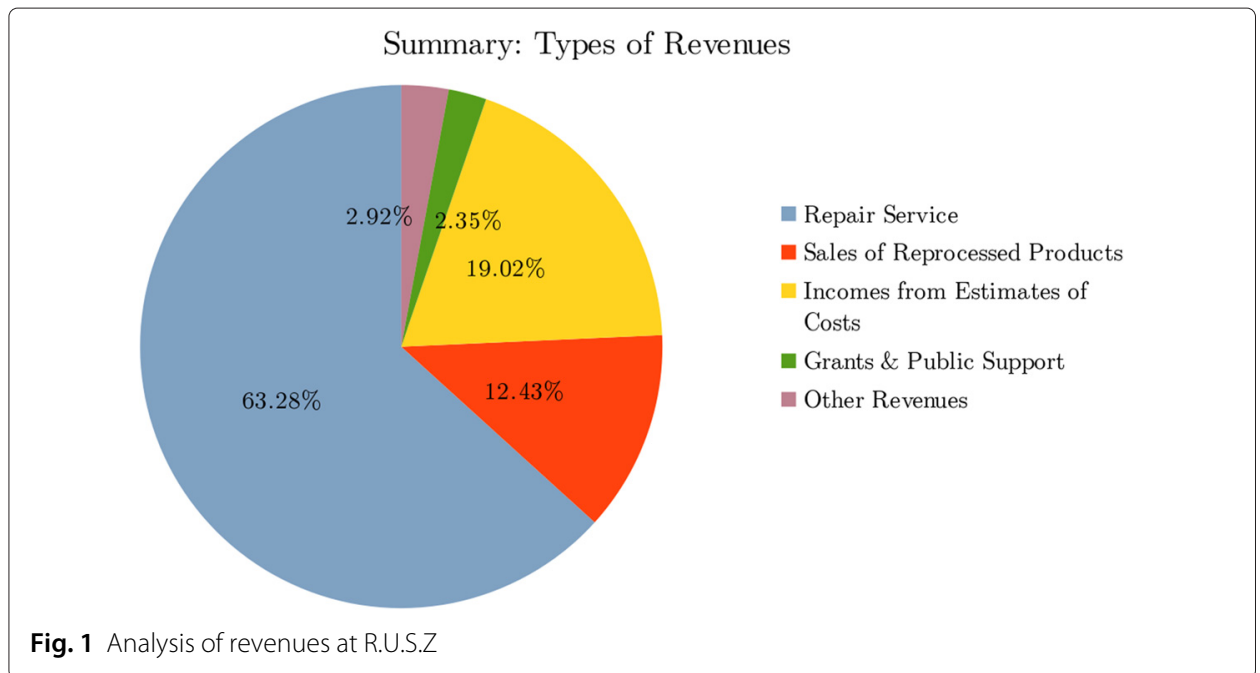

shows that the repair service is by far the biggest business: more than $63 \%$ of the total annual revenue of about $€ 800,000$ in 2014 stem from this sector. Related to this, nearly $20 \%$ of the income comes from estimates of costs, which are offered in order to determine a potential economically viable reparability. The third largest revenue with more than $12 \%$ share is generated by selling reprocessed goods. Interestingly, grants and public financial support account only for $2.35 \%$ of total revenue.

While R.U.S.Z' total business including all branches is profitable, reprocessing activities per se are not cost-covering. Though, as the same working abilities are required for repairing and reprocessing, the segment can be seen as an appropriate complement to the provided repair service.

Taking a look at the shares of different types of costs shown in Fig. 2 provides some insights into the cost structure at R.U.S.Z (data is solely available on an aggregated level for all activities). It is obvious that due to the high degree of manual work the main item of expenditure is costs for staff. Further types of costs exceeding $10 \%$ of total costs are 'Rent and other Operating Costs' and 'Production Costs', while all other amount to less than $5 \%$.

In summary, due to the hardly obtainable cost coverage reprocessing of white or brown goods rather fits for non-profit organizations of the Work Integration Social Enterprises with financial support from the government. For small-scaled, independent, private companies with limited output economic sustainability is hard to achieve by only focusing on reprocessing of these products. Finally, an economic side-effect of the offered services is the local value creation: contrary to producing new goods, which is mainly outsourced abroad, the added value remains inland.

\section{Energy efficiency and environmental impact of R.U.S.Z' activities}

The energy-saving method 'Tuning of Washing Machines' developed by R.U.S.Z used for upgrading products increases the energy efficiency category of washing machines and improves the energy efficiency category from, e.g., $\mathrm{C}$ to $\mathrm{A}$. This can be achieved by a reduction of water consumption resulting in energy demand of around $20 \%$. In detail, in case of washing machines the energy-intensive water heating can be optimized by reducing the total water consumption. Consequently, the total energy consumption for heating 


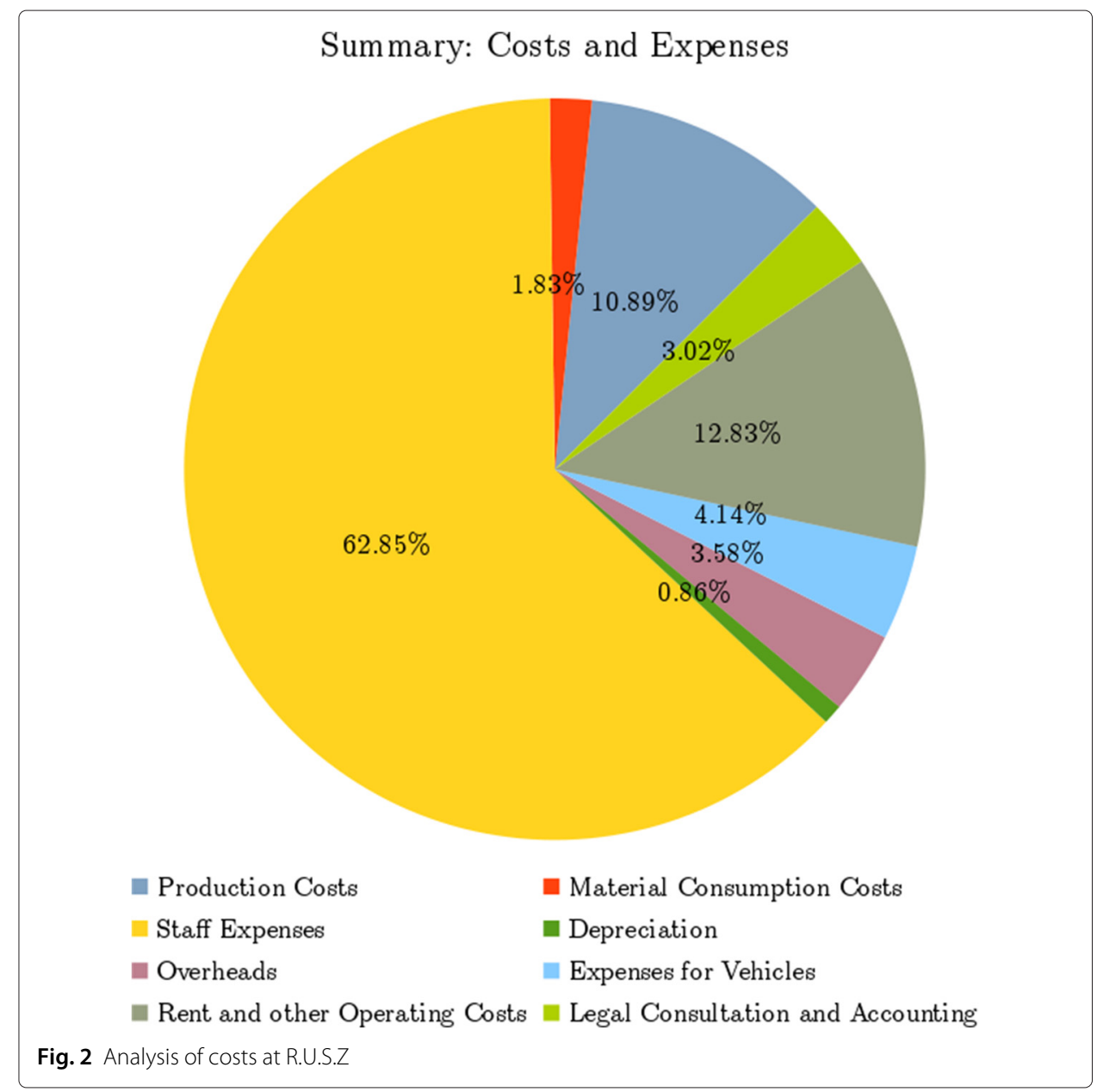

the water is decreased, while the quality of the washing process remains at the same level. However, as the supply with washing machines with an energy efficiency category of $\mathrm{C}$ declines due to the fact that nearly all of these have been returned and replaced by better ones, upgrading washing machines will vanish in near future.

As a side effect of reprocessing used products, environment is impacted by the extension of the product usage phase of a reprocessed product by about ten years. Selling remanufactured/refurbished products induces a postponement of the resource consumption for producing new products. Additionally, the second life of reprocessed products including a related extended usage phase potentially reduces the overall consumption of resources. Contrary to these resource savings from an extended life cycle, potential environmentally friendly innovations must be considered to get a holistic view on the environmental impact. These innovations may decrease the resource consumption of new products in the usage phase and reduce or even (over)compensate benefits from an extended usage phase. For an overview of the ongoing scientific discussion concerning the eco-efficiency of refurbishment of white goods we refer to [9-11].

\section{Reverse logistics for white goods at R.U.S.Z}

One of R.U.S.Z' main businesses - besides offering repair services for household appliances, consumer electronics, and computers - is reprocessing of used white goods, mainly 
washing machines, dishwashers, ovens, dryers, and washer-dryers. Used white goods come from different sources of supply: on the one hand, private persons can donate their (even not working) products to R.U.S.Z. Recurring media campaigns remind the Viennese public of this possibility. As it is sponsored by the Viennese municipality, R.U.S.Z can offer a low-priced collection service. This enables the acquisition of used machines which are at the end of their first usage phase and therefore sorted out by private persons. By offering a collection at the customer's home, staff can already pre-sort and pre-classify the white goods as reusable/non-reusable by identifiable characteristics (e.g., visual inspection of the condition of the casing, indication of malfunction). On the other hand, R.U.S.Z cooperates with commercial collectors of electrical and electronic equipment, which provide them with used items. However, as these cooperations currently result in negligible quantities of used products, we do not consider them in this work.

After transportation to the reprocessing site, the machines are manually tested and sorted with respect to their further usability. Reusable products are classified in one out of three categories based on specific quality criteria, while non-reusable items are either determined for spare parts recovery or disposal/recycling. Up to the result of this sorting/grading/test procedure, the products are remanufactured and optionally upgraded, refurbished, cannibalized to extract spare parts, or recycled. The option to upgrade a product results in an improved energy efficiency category of a washing machine, based on an energy-saving method developed by R.U.S.Z. After reprocessing, the reusable white goods are offered in the R.U.S.Z-shop as second-life products. Thus, customers can buy, e.g., a reprocessed washing machine with a life expectancy of - according to R.U.S.Z - ten years at a reduced price which is comparable to a new, low-quality washing machine.

In Fig. 3, a process map concerning the reverse logistics at R.U.S.Z is shown. All of the activities and processes are discussed in detail in Section 'Discussion and evaluation'.

\section{Methodology}

The first contact with the head of R.U.S.Z, Mr. Eisenriegler, was in the course of an invited talk and a subsequent discussion at the University of Graz. This was the stimulus for a cooperation and led to this scientific exploration of the reverse logistics at R.U.S.Z.

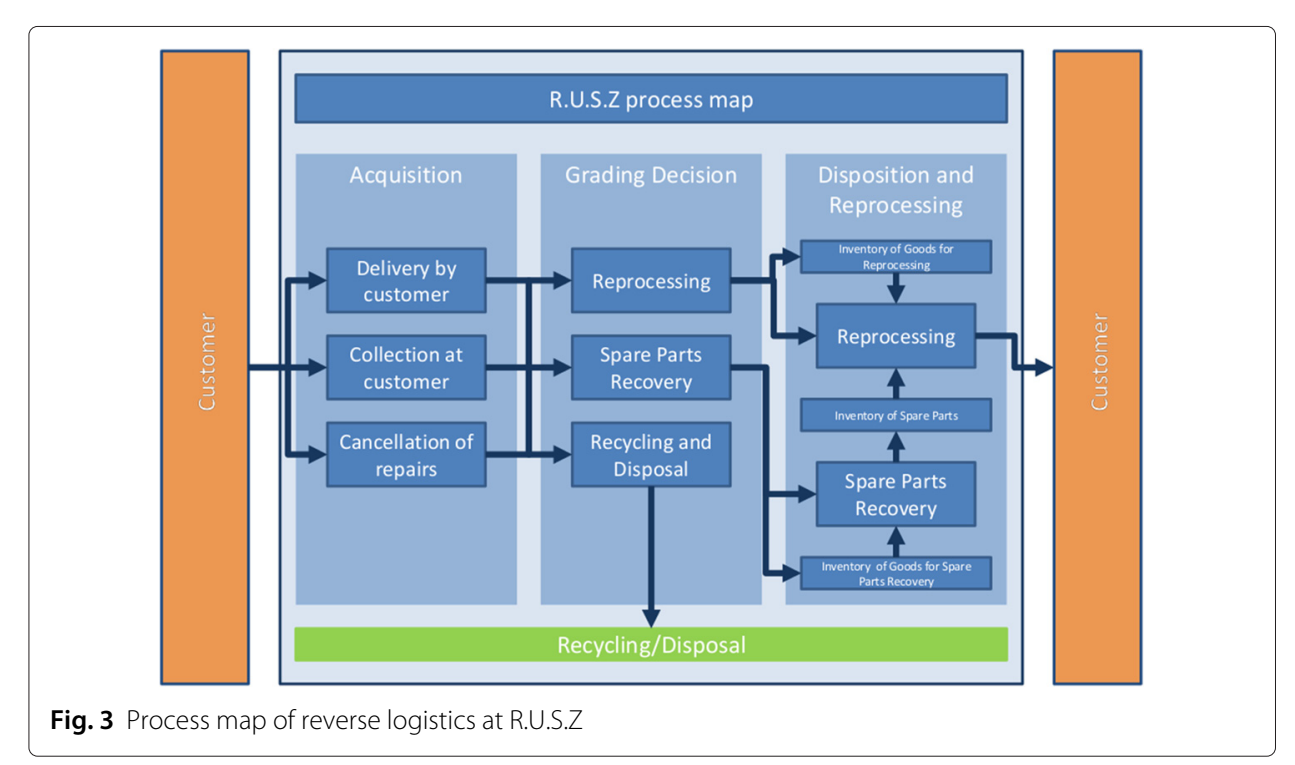


Regarding the methodology, we decided to use case study research due to several factors. Case study research has played an important role for the development of research in the area of reverse logistics and closed-loop supply chains (RL/CLSC). Well-known examples for case studies giving impulses for scientific work are about IBM [12] and ReCellular Inc. [13]. Furthermore, a review of case studies in the area of reverse logistics is presented in [14].

Yin considers a case study as an empirical inquiry that investigates a contemporary phenomenon in depth and within its real-life context' [15]. Due to several reasons given below, an in-depth, explorative case study is an adequate methodology to deal with the investigation of R.U.S.Z. First of all, using explorative case study research is supported by the fact that NPOs with entire reverse logistics processes from acquisition of used products to remarketing can rarely be found. Next, the case study allows to get a holistic view on processes and decision-making of R.U.S.Z. Both the holistic view and the type of questions ('what?', 'how?') favor the case study method. Additionally, R.U.S.Z can not be studied without considering its case-specific context; for example, the complex acquisition of used products and the sale of reprocessed products instead of new ones with consequential questions regarding warranty or pricing have to be included and studied in the case study to guarantee an overall understanding. Finally, the case of R.U.S.Z is an investigation of a contemporary phenomenon. All of these arguments are in line with literature related to case study research (see, e.g., [15-17]).

The R.U.S.Z - case study is mainly based upon a company visit on April 24th, 2013, including interviews with the head of R.U.S.Z and an employee. Questions asked during the interviews are based upon an intense literature review to identify characteristics already known in the scientific community. Furthermore, the guideline of questioning prepared for the interviews followed the generic reverse logistics flow established in research literature (e.g., the processes acquisition, grading, and disposition of used products [18]). This procedure allows and supports us to find differences compared to standard process models used in scientific literature. We conducted a semi-structured interview with the head of R.U.S.Z (duration: 150 minutes), consisting of open-ended questions; with this approach we were trying to get a holistic view on R.U.S.Z' business and decisions. The main focus was on the logistics processes, decision-making, and challenges for R.U.S.Z, both on a strategic and an operational level of business. Furthermore, a company tour tracking the processed items helped to clarify and make sure the logistics processes and flow of material at R.U.S.Z. In the course of this company tour, another interview with a duration of 15 minutes was conducted with an employee responsible for receiving and classifying of acquired used products. The interviews were conducted in German, and the information was documented directly by detailed handwritten notes.

Next to interviews, some additional data sources were available. R.U.S.Z publishes yearly reports concerning their business development. These reports include data from operations and descriptions of the strategic concepts. Furthermore, data could be gathered at presentations given by Mr. Eisenriegler, the head of R.U.S.Z. Finally, R.U.S.Z provided us with the entire business database of the day-to-day business, including datasets for the years 2011, 2012, and 2013. This database contains detailed information regarding operations, e.g., delivery dates, quality of returned used products, decision-making, and completion dates. 
Two additional phone calls helped to clarify ambiguous information: on the one hand, the scope of the case study was extended to include information concerning customer preferences and the consequences on pricing of reprocessed goods. On the other hand, in the course of the analysis of the business database a further clarification regarding datasets was required. Due to validity reasons, the case study was given to R.U.S.Z to recheck all the information.

\section{Discussion and evaluation}

In this section, some observations and key figures regarding R.U.S.Z are presented, including organizational, logistical and ecological topics. As described above, the information is based upon R.U.S.Z' yearly reports, several discussions with employees and the head of R.U.S.Z, and the business database of the day-to-day business.

\section{Integrated reverse logistics and decision-making at R.U.S.Z}

Reverse logistics consists of different aspects, in detail, acquisition of used products (supply), grading, subsequent disposition decisions and reprocessing, and finally, remarketing of reprocessed products. Clearly, the individual processes at R.U.S.Z can not be considered as isolated activities, as there exist interdependencies between the processes. First of all, the acquired quantity of used products determines the maximum amount of reprocessed products. Next to the used products which are prepared for reuse, some additional products have to be acquired to ensure a sufficient supply with spare parts needed for reprocessing activities. However, the more products R.U.S.Z acquires, the higher is the total effort which has to be spent to determine the qualitative condition of the used products. Besides the fact that the cost for reprocessing correlates negatively with the quality of the acquired and classified product, the result of the classification restricts the possible reprocessing options. All the reverse logistics activities - acquisition, grading, as well as disposition and reprocessing - use resources and are subject to capacity restrictions.

These activities have to be balanced and allocated carefully to the available reprocessing capacity. For example, there is a trade-off between grading and reprocessing which has to be considered. Exorbitant classification of used products is not effective, as these graded goods could not be reprocessed due to limited capacity. Therefore, the excessive grading results in wasted resources, which could be used for acquisition or reprocessing instead of (futile) grading. Contrary to that, it may be useful to overproduce and store reusable products or spare parts in a period to avoid capacity bottlenecks in subsequent periods.

The decision-making at R.U.S.Z is not based upon decision support systems or optimization approaches but on experience. The actual decisions depend on the present situation concerning workload and capacities. Regarding the acquisition process, R.U.S.Z acquires all available white goods, without any limit. After the acquisition, the used products are promptly classified in a grading process. The grading of products by using defined criteria (condition, brand, age) results in items being either used for reprocessing/spare parts recovery or - after classification as non-reuseable - directly recycled. Used products classified as reprocessable are reprocessed, while the remaining reusable goods are used for spare parts recovery.

Thereafter, the decision on further treatment of classified products selected for reprocessing is mainly based on the current workload: if capacity in terms of staff is available, the items are immediately treated in their determined way. Otherwise, the products are 
stored. Additionally, R.U.S.Z has experience concerning the items which are in demand; naturally, this also influences the reprocessing decision.

In the course of reprocessing activities, efforts are made to reprocess the item in the designated way. However, due to grading errors the used item may not be brought to the intended quality level (see Sections 'Grading process/quality of used products' and 'Disposition process and reprocessing activities' for details regarding the grading and disposition).

The quality of the reprocessed product is quantified by visual and safety inspections and functional tests. At the final stage of reprocessing, remanufactured products classified as class 1 can be assumed to be in quasi-mint condition, while class $2 / 3$-items can be considered as refurbished, as they meet the specified minimum criteria. The decreasing quality levels of the different product classifications correlate with declining sales prices.

Concerning spare parts, there is no superior strategy which spare parts to collect. The recovery process is executed by acting as one thinks best, so workers dismantle parts considered as being suitable. Due to the absence of a warehouse management system, neither the quantity nor the quality of available spare parts can be determined exactly. Nevertheless, acquisition of used products, grading, disposition, and spare parts management are interrelated, what is illustrated by the following two examples: for instance, without sufficient supply with used products both reprocessing and spare parts recovery are disrupted. Furthermore, an inefficient grading process may lead to a huge bulk of reprocessable items, but simultaneously also to a lack of spare parts needed for reprocessing those products. Actually, these characteristics lead to stockout events at R.U.S.Z. From time to time, the company faces situations when certain spare parts are out of stock, what entails the interruption of reprocessing activities and a search for appropriate spare parts.

Available used products differ in brands, age, and condition. Clearly, these differences affect the further reprocessing possibilities of the items. Nevertheless, spare parts often can be used for multiple brands.

The reprocessing activities have to be considered over time, as the supply with used products and the demand for reprocessed goods vary throughout the year, but inventory and reprocessing capacities remain more or less static. For example, manual work power is restricted: therefore, the products processed using these capacities have to be balanced over time. Consequently, tasks like spare parts extraction or reprocessing may be done in previous periods without effective demand to ensure the supply with reusable products and spare parts in future periods.

Finally, the reprocessed products are sold as second-life products in the on-site showroom. For all of the resold items, a warranty of one year is provided.

\section{Supply with used products}

R.U.S.Z receives used products from different sources of supply for reprocessing activities. In Table 1, the supply sources for reprocessed products in 2011, 2012, 2013 and total supply (2011 \& 2012 \& 2013) are listed: next to customers who delivered their used products, the collection service at the customer's home was the main source of supply. Acquisition quantities coming from both of those sources of supply can be actively influenced by taking costly measures, for example by a fee for the pick-up service or by effort for advertisement and information. This also explains the fact that the amount of acquired used products declined in 2013 by about $40 \%$ compared with 2012 . 
Table 1 Sources of supply in 2011,2012,2013

\begin{tabular}{lllll}
\hline & 2011 & 2012 & 2013 & Total \\
\hline Delivery by customer & $631(46.5 \%)$ & $639(49.3 \%)$ & $416(53.3 \%)$ & $1,686(49.1 \%)$ \\
Collection at customer & $374(27.6 \%)$ & $405(31.2 \%)$ & $191(24.4 \%)$ & $970(28.2 \%)$ \\
Products on stock & $107(7.9 \%)$ & $26(2.0 \%)$ & $0(0.00 \%)$ & $133(3.9 \%)$ \\
Cancellation of repairs & $245(18.0 \%)$ & $227(17.5 \%)$ & $174(22.3 \%)$ & $646(18.8 \%)$ \\
Sum & 1,357 & 1,297 & 781 & 3,435 \\
\hline
\end{tabular}

The enormous decrease was caused by the reduction of effort spent for public relation to acquire used products due to the prioritization and growth of the business segment 'repair services' in 2013.

There are two additional sources of supply for reprocessing items. On the one hand, R.U.S.Z has pre-sorted white goods on stock, as the acquisition and reprocessing of white goods started before 2011. All used goods which are classified as reprocessable but not reprocessed immediately after their arrival at R.U.S.Z are stored. Therefore, these products are an additional supply source for reprocessing. On the other hand, as R.U.S.Z offers a repairing service, people sometimes cancel the planned repair and donate the white goods instead of spending money for a costly repair. Interestingly, the amount of reprocessed items coming from inventory declined significantly in 2012 and 2013 compared with 2011. Despite this fact, the absolute number of products from the remaining three sources remained at a comparable level or increased in 2012. In 2013, the percentage values of the three sources of supply were similarly distributed. The reason for the decrease of reprocessed stocked items is the rising business concerning the repairing services. The used products coming from stock are solely reprocessed in situations when there is not enough work (in terms of repair services or reprocessing of recently acquired used products) to keep the staff busy. Thus, these stocked items are used for balancing the workload.

Since 2012, R.U.S.Z has demanded a fee of $€ 9$ for the pick-up service, compared with $€ 24$ in the year 2011. This price reductions was possible as the municipality of Vienna sponsors the pick-up service. The amount of collections at customers' homes increased in the year 2012 compared with 2011 by about $8 \%$, but dropped by about $53 \%$ in 2013 due to the decreased effort. Naturally, in these circumstances it is impossible to analyze these results in detail; however, according to R.U.S.Z, the reduction of the collection fee has a positive effect on the amount of items received. This assumption of a positive effect is supported by some indirect indicators: for instance, the number of complaints regarding the collection fee decreased significantly. An additional example is that refusals of donations due to the fee were reduced to almost zero. Nevertheless, the main intention of demanding a collection fee is to act as an inhibition, as it should prevent the misusage of R.U.S.Z' services as free waste collection.

However, the question remains if a decreased pick-up fee results in an increased total number of available used items: collections at the customers may simply substitute deliveries by customers due to lower cost. Consequently, instead of increasing the total number of acquired goods, only the fraction of used products delivered by customers would decline.

The acquired/returned quantity fluctuated throughout the year, although the pick-up fee and similar efforts to control the return flow remained the same in the course of the year (see Table 2 for data on a monthly base). The hypothesis that the monthly aggregated 
Table 2 Absolute receivings per supply source and month (Delivery by customer: Dbc, Collection at customer: Cac, Products on stock: Pos, Cancellation of repairs: Cor)

\begin{tabular}{|c|c|c|c|c|c|c|c|c|c|c|c|c|c|c|c|}
\hline & \multicolumn{3}{|c|}{$\mathrm{Dbc}$} & \multicolumn{3}{|c|}{$\mathrm{Cac}$} & \multicolumn{3}{|c|}{ Pos } & \multicolumn{3}{|c|}{ Cor } & \multicolumn{3}{|c|}{ Sum } \\
\hline & 2011 & 2012 & 2013 & 2011 & 2012 & 2013 & 2011 & 2012 & 2013 & 2011 & 2012 & 2013 & 2011 & 2012 & 2013 \\
\hline Jan & 45 & 51 & 42 & 33 & 4 & 40 & 6 & 0 & 0 & 32 & 9 & 11 & 116 & 64 & 93 \\
\hline Feb & 24 & 82 & 48 & 81 & 1 & 22 & 1 & 0 & 0 & 22 & 17 & 18 & 128 & 100 & 88 \\
\hline Mar & 19 & 67 & 12 & 58 & 9 & 14 & 3 & 0 & 0 & 22 & 11 & 9 & 102 & 87 & 35 \\
\hline Apr & 41 & 43 & 39 & 32 & 42 & 44 & 26 & 0 & 0 & 13 & 19 & 10 & 112 & 104 & 93 \\
\hline May & 31 & 51 & 31 & 45 & 83 & 19 & 19 & 0 & 0 & 15 & 18 & 4 & 110 & 152 & 54 \\
\hline Jun & 43 & 58 & 7 & 33 & 52 & 0 & 12 & 26 & 0 & 18 & 22 & 4 & 106 & 158 & 11 \\
\hline Jul & 23 & 36 & 76 & 40 & 55 & 1 & 2 & 0 & 0 & 15 & 28 & 1 & 80 & 119 & 78 \\
\hline Aug & 48 & 36 & 55 & 20 & 24 & 6 & 0 & 0 & 0 & 19 & 18 & 15 & 87 & 78 & 76 \\
\hline Sep & 76 & 71 & 26 & 18 & 35 & 22 & 28 & 0 & 0 & 16 & 32 & 23 & 138 & 138 & 71 \\
\hline Oct & 112 & 66 & 20 & 10 & 45 & 15 & 0 & 0 & 0 & 36 & 24 & 12 & 158 & 135 & 47 \\
\hline Nov & 125 & 54 & 23 & 4 & 39 & 2 & 0 & 0 & 0 & 21 & 19 & 17 & 150 & 112 & 42 \\
\hline Dec & 44 & 24 & 37 & 0 & 16 & 6 & 10 & 0 & 0 & 16 & 10 & 50 & 70 & 50 & 93 \\
\hline Sum & 631 & 639 & 416 & 374 & 405 & 191 & 107 & 26 & 0 & 245 & 227 & 174 & 1,357 & 1,297 & 781 \\
\hline
\end{tabular}

quantities may be uniformly distributed is not supported (tested with $\chi^{2}$-test), neither for 2011 or 2012 nor for 2013. Therefore, non-uniformly distributed, stochastic supply patterns can be assumed.

Interesting results can be observed regarding the correlation coefficients of the monthly acquired used goods in the individual years: while 2011 and 2012 correlate positively with respect to the monthly values (correlation coefficient of 0.44373 ), the remaining comparisons show negative correlation coefficients (2011 vs. 2013: $-0.28523,2012$ vs. 2013: $-0.61885)$. This can be interpreted as similarities of supply patterns or seasonal effects in 2011 and 2012, but an inverse supply pattern in 2013.

A graphical representation of the supply variability throughout the year regarding acquired quantities in 2011, 2012, 2013, and in total can be found in Fig. 4. In 2011, the relative amount/month ranges from $5.16 \%$ to $11.64 \%$. Similarly, the relative acquired quantity/month ranges from $3.86 \%$ to $12.18 \%$ in 2012 and from $1.41 \%$ to $11.91 \%$ in 2013 , respectively.

As indicated by the correlation coefficient, the years 2011 and 2012 - and following from those years, the combined view on data considering all years - indicate seasonal effects. Besides the obvious effect of holidays in July and August, which results in a low of acquired products, peaks can be found in February, May/June, and September - November. In December/January as well as in March the acquisition quantities are significantly lower. Nevertheless, some stochastics is still included in these fluctuations. The distribution of supply in 2013 differs from those in the preceding years: while still a peak can be found at the beginning of the year, the remaining months show a reverted development. For instance, contrary to 2011 and 2012 the amount of acquired used products reaches the maximum at the end of the year.

Based upon an estimation before the project started, R.U.S.Z expected a higher acquisition amount than the actual one. Next to the fee for the collection service, there are several reasons for the low acquisition quantity.

First of all, in 2010 customers got a government-funded bonus if they traded in their used product for a new, energy-efficient one. In order to get the money, the used products had to be returned to a retailer or a designated collection center. As R.U.S.Z was 


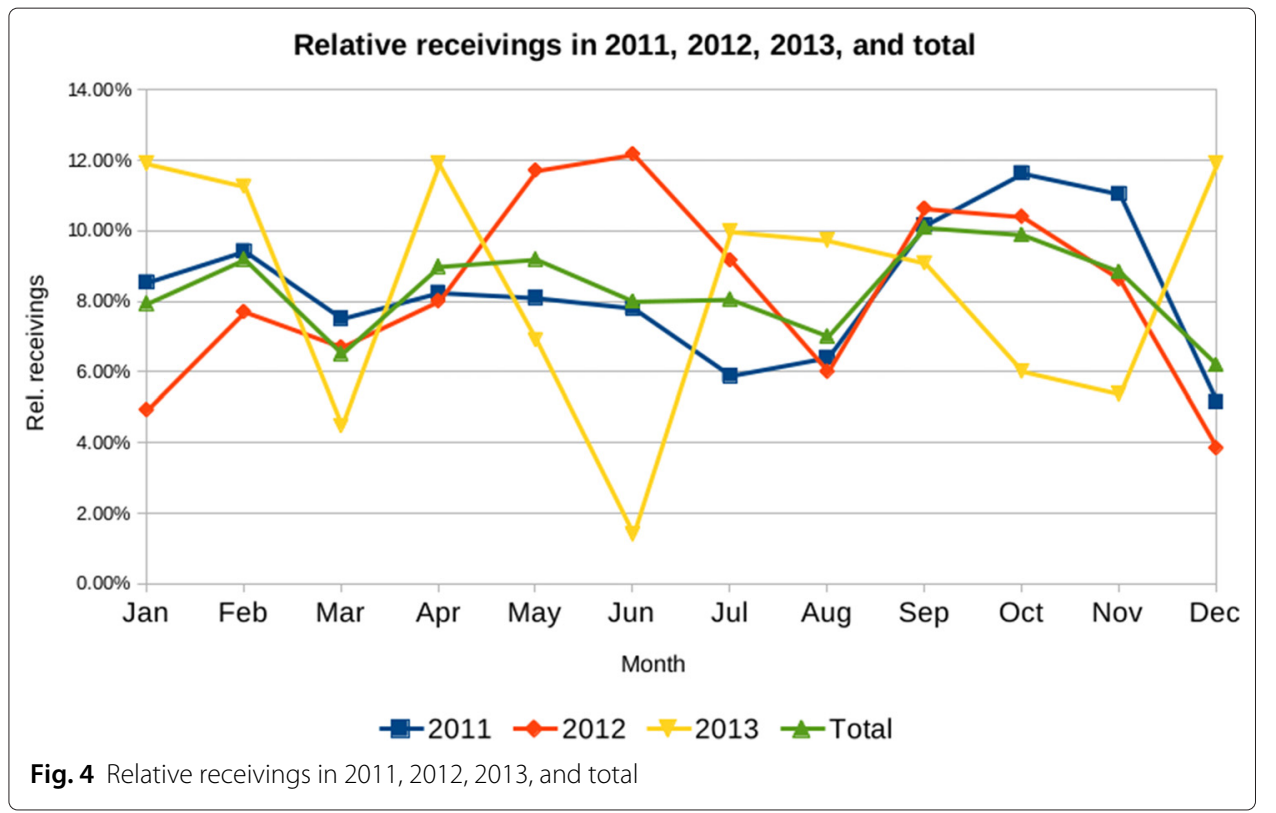

not considered as an appropriate collection center, all reprocessable and reusable used products exchanged in the course of this measure could not be acquired. Additionally, the bonus stimulated the replacement of used goods. This led to early purchases and a reduced amount of used items available in subsequent years. Another reason is that potential donators often prefer the concurrent collection and removal free of charge offered by chain of stores in case new consumer electronics/white goods are bought and delivered. Finally, chain of stores deny a cooperation with R.U.S.Z in terms of allocation of used products due to potential cannibalization of their share in the market caused by reprocessed items. According to Austria's market leader in the area of electrical and electronic products, all of the used products acquired by chain of stores are disposed of professionally (Personal communication with Saturn Customer Service on Jun. 18th, 2013). Consequently, this also reduces R.U.S.Z' supply with used and potentially reprocessable goods.

The potential number of white goods for acquisition in Vienna can be estimated based upon the annual sales volume. In Austria, around 1,350,000 new white goods are sold per year [19]. This includes about 250,000 used washing machines which are exchanged with new ones [20]. Although R.U.S.Z is located in Vienna and focusing their business on this region, a considerable amount of used white goods would be available, supplied by different sources. The amount of these yearly exchanged used white goods can be estimated roughly by comparing the number of households in Vienna (without surrounding area: $0.863 \mathrm{~m}$ ) with the number of households in Austria (3.678 m) [21]: consequentially, around 317,000 white goods (including about 58,700 washing machines) can potentially be acquired per year. Furthermore, assuming that each household owns a washing machine, the average usage phase until a washing machine is replaced is about seven years (number of households/exchanged used washing machines).

\section{Grading process/quality of used products}

Acquired used white goods are graded in the course of two different activities. On the one hand, products picked up at the customer's home are preselected and roughly graded 
as reusable or non-reusable, depending on their condition; for instance, a rough visual inspection of the condition of the casing is performed, or indications of malfunction are documented. On the other hand, a manual grading, sorting, and classifying process is performed for all products right after arriving at R.U.S.Z. This classification is mainly based upon a visual inspection, which is conducted by skilled and experienced staff. In the course of this grading process, all reusable used products are classified in three categories (class 1/2/3), depending on brand, condition, and age. Branded goods in a good shape up to specified ages are graded as class 1 (high quality, so-called 'raisins', e.g.: Miele, max. 20 years, passed visual inspection) or class 2 (medium quality, also referred to as 'potential', e.g.: Eudora, any age, no oxidation, passed visual inspection), while the remaining reprocessable products belong to class 3 (low quality, named 'social', e.g.: various branded goods, easy to repair, passed visual inspection). Nevertheless, reusable products classified as class 1, 2, 3 can also be used for spare parts recovery. The non-reusable items are classified as products for spare parts recovery or recycling/disposal. Afterwards, the classified used products are either placed into stock, reprocessed, cannibalized, or collected for material recycling. However, since October 2012 R.U.S.Z has stopped preparing class 3 -items for reuse almost totally, as refurbishing these products is not cost-covering due to the low sales prices. Additionally, the limits for reprocessing class 2-items have been tightened.

One main issue is the error-proneness of the grading process: due to the fact that a detailed check including testing all parts is not conducted at the grading stage, the classification does not always match the possible reprocessing options. Thus, as the grading process and the reprocessing step are separated, differences between the planned and the actual disposition decision occur (refer to Section 'Error-proneness of the grading process' for a detailed analysis concerning grading errors).

Figure 5 presents the proportion of the respective classification results. In both 2011 and 2012, the main part of the acquired items was classified as reusable, whereby class 3 -products were observed most. About $25 \%$ of the goods were collected and directly recycled. In 2013, most of the parts were recycled due to the strategy change with related focus on high-quality items, while the relative amount of class 1-items remained at about the same level. In 2012 and 2013, the amount of items chosen for spare parts recovery increased significantly compared with 2011 . This can be explained by the modified business strategy: as mentioned above, reprocessing class 2-products and class 3-items is not cost-covering in the majority of cases. Instead of reprocessing these goods R.U.S.Z focuses on the strictly selected class 1 and uses class $2 / 3$-items mainly for spare parts collection. Thus, the amount of products for spare parts recovery raised and the quantity classified as class 3 decreased compared with before.

In Table 3, the distribution of the product qualities throughout the years 2011, 2012, and 2013 is shown. The amount of acquired products of a quality category greatly differs from month to month: for example, in 2011, the quantity of acquired and classified class 1-products ranges from 3 to 34, resulting in a sum of 225 items. An interesting increase of recycled items can be observed in Aug. - Dec. 2011: due to excessive stocking up with reprocessable items, the storage capacity exhausted. Thus, R.U.S.Z sorted out stocked used products in a comparably poor quality to create space for new acquired products in a better condition. Interestingly, although the total number of items, the units recycled and the class 2-/class 3-products decreased in 2012 compared with 2011, the amount of 


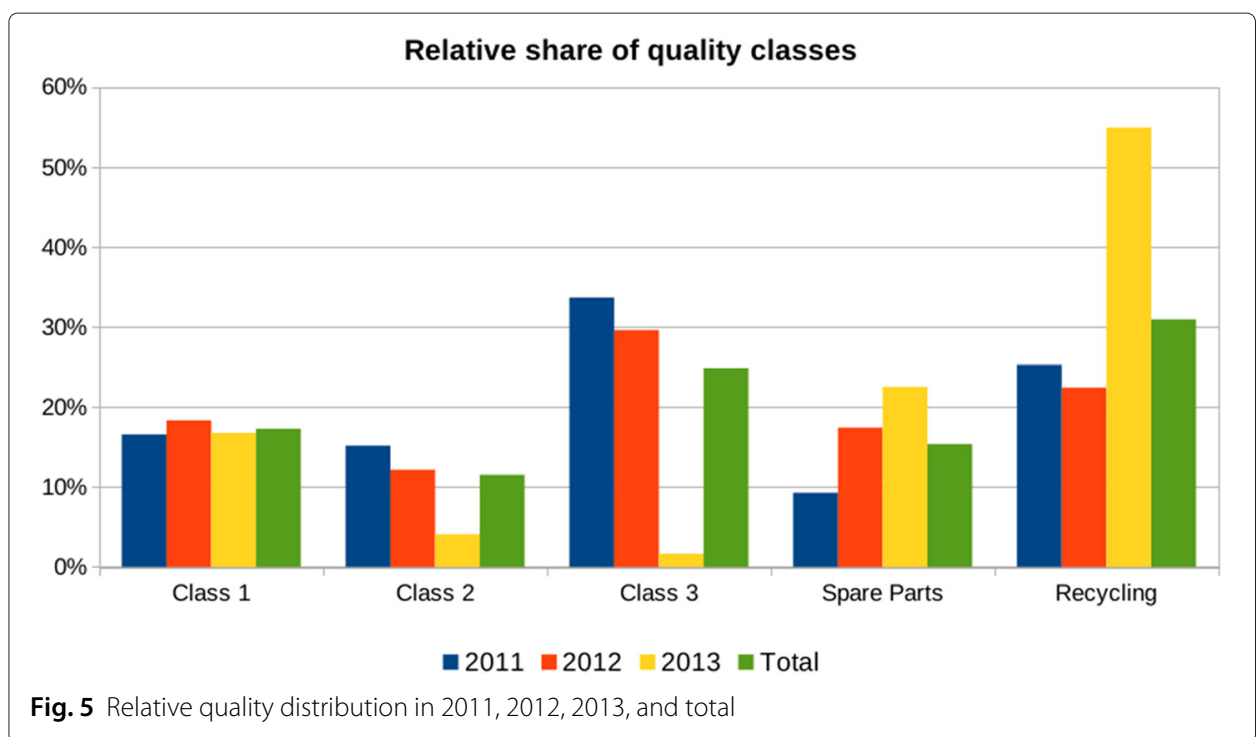

class 1-products increased. This may be explained by the increased consumer awareness to return only high-quality items, as this is promoted by R.U.S.Z. As mentioned above, the total supply with used white goods declined in 2013. Contrary to that, the quantity of recycled items is - in absolute values - the largest in that year. Simultaneously, the number of items classified as class 2 or class 3 dropped. Both effects are results of the strict selection strategy concerning the two quality classes. Naturally, also the amount of needed spare parts reduces with a decreasing number of reprocessed items.

\section{Disposition process and reprocessing activities}

In this section, the reprocessing activities are described in detail. Acquired used products can be remanufactured and - optionally - upgraded, refurbished, cannibalized to extract spare parts, or recycled. According to R.U.S.Z, the main cost driver for all types of reprocessing and spare parts recovery is the manual workload, as automation fails due to the variety of error types and the resulting complexity. The second-ranked cost driver is the

Table 3 Quality grading of receivings in 2011, 2012, and 2013

\begin{tabular}{|c|c|c|c|c|c|c|c|c|c|c|c|c|c|c|c|}
\hline & \multicolumn{3}{|c|}{ Class 1} & \multicolumn{3}{|c|}{ Class 2} & \multicolumn{3}{|c|}{ Class 3} & \multicolumn{3}{|c|}{ Spare Parts } & \multicolumn{3}{|c|}{ Recycling } \\
\hline & 2011 & 2012 & 2013 & 2011 & 2012 & 2013 & 2011 & 2012 & 2013 & 2011 & 2012 & 2013 & 2011 & 2012 & 2013 \\
\hline Jan & 20 & 10 & 23 & 25 & 17 & 5 & 43 & 27 & 1 & 11 & 3 & 45 & 17 & 7 & 19 \\
\hline Feb & 23 & 17 & 26 & 25 & 16 & 4 & 45 & 41 & 3 & 25 & 22 & 34 & 10 & 4 & 21 \\
\hline Mar & 19 & 17 & 6 & 22 & 8 & 0 & 40 & 34 & 0 & 12 & 12 & 1 & 9 & 16 & 28 \\
\hline Apr & 21 & 17 & 16 & 19 & 14 & 3 & 39 & 48 & 0 & 13 & 14 & 20 & 20 & 11 & 54 \\
\hline May & 33 & 27 & 10 & 21 & 25 & 1 & 37 & 50 & 1 & 11 & 16 & 22 & 8 & 34 & 20 \\
\hline Jun & 17 & 19 & 3 & 21 & 10 & 0 & 37 & 54 & 2 & 26 & 40 & 3 & 5 & 35 & 3 \\
\hline Jul & 5 & 24 & 26 & 19 & 17 & 6 & 47 & 37 & 2 & 6 & 20 & 0 & 3 & 21 & 44 \\
\hline Aug & 9 & 17 & 7 & 3 & 10 & 3 & 17 & 23 & 0 & 1 & 7 & 31 & 57 & 21 & 35 \\
\hline Sep & 8 & 21 & 8 & 7 & 21 & 4 & 29 & 42 & 3 & 0 & 17 & 5 & 94 & 37 & 51 \\
\hline Oct & 33 & 33 & 6 & 22 & 9 & 2 & 37 & 10 & 1 & 9 & 18 & 7 & 57 & 65 & 31 \\
\hline Nov & 34 & 25 & 0 & 14 & 8 & 0 & 61 & 12 & 0 & 4 & 35 & 4 & 37 & 32 & 38 \\
\hline Dec & 3 & 11 & 0 & 8 & 3 & 4 & 25 & 6 & 0 & 8 & 22 & 4 & 26 & 8 & 85 \\
\hline Sum & 225 & 238 & 131 & 206 & 158 & 32 & 457 & 384 & 13 & 126 & 226 & 176 & 343 & 291 & 429 \\
\hline
\end{tabular}


material cost in terms of recovered - or even new - spare parts. Another aspect concerning costs is that a high-quality product causes less reprocessing cost than a used item in a bad condition; thus, reprocessing cost correlates negatively with the quality of a product. R.U.S.Z traces this back to several reasons: products classified as reusable are typically manufactured by brands which design durable and robust products. Usually the design of those products allows a faster replacement of broken parts compared with non-branded goods due to an eased accessibility. Consequently, reprocessing causes less labor cost. Furthermore, the brands are often market-dominating and have big shares in the market. Thus, a large proportion of the acquired products are branded goods, and consequently, appropriate spare parts can be recovered cost-efficiently.

\section{Reprocessing procedures}

A product as good as new can be obtained by applying a remanufacturing process to a used product. In the case of R.U.S.Z, the average additional usage phase of a reprocessed and, in particular, remanufactured item is about 10 years. As the remanufacturing process is expensive and time-consuming due to the complexity of the process and the resulting large proportion of required manual work, only the used products classified as class 1 - which indicates an excellent condition of the returned item and consequently low remanufacturing cost - are chosen for this process. While the average time needed to remanufacture an item is one hour, the effort varies between 30 minutes to 3 hours, depending on the condition of the product.

Refurbishing a product means to improve the quality condition of a used item so that specified minimum quality requirements are fulfilled. Different from the items undergoing a remanufacturing process, a refurbished product is observably a used product. However, in case of R.U.S.Z, refurbishing a used item needs similar resources as remanufacturing with required manual work time of 30 minutes to 3 hours and an average reprocessing time of about one hour. Potentially, most of the refurbished goods could be remanufactured by spending a much higher effort, which would result in an excessive cost-intensive reprocessing. Although the refurbished products can be sold only at a lower price than remanufactured ones, the refurbishment is profitable and does pay off.

The upgrading/tuning process can be applied to reprocessed class $1 / 2$ - products within one hour of working time and results in an upgraded product with an increased performance compared with the original. Thus, upgrading is an innovative process, which improves the product compared with the original product and provides some additional benefit, e.g., in terms of saving energy (see Section 'Energy efficiency and environmental

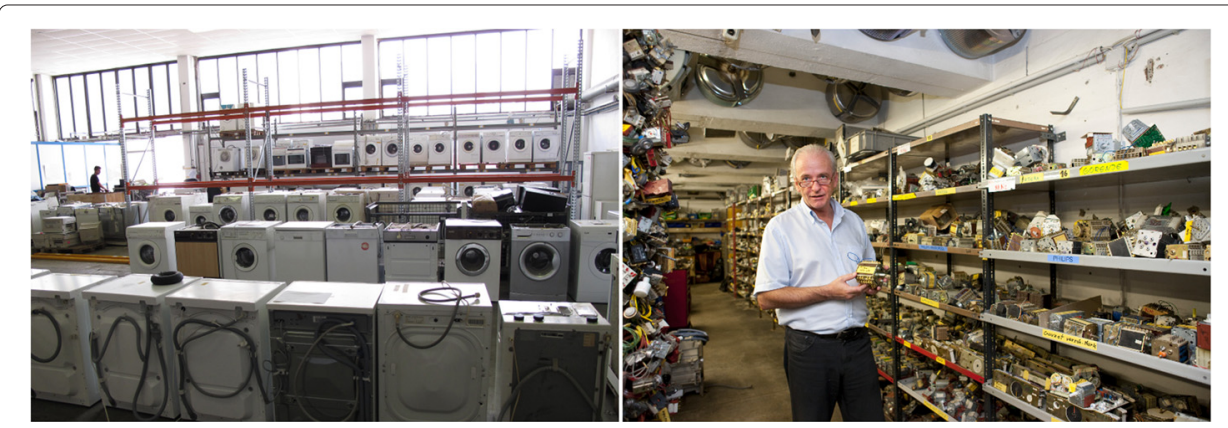

Fig. 6 White goods and spare parts inventory (Source: R.U.S.Z) 


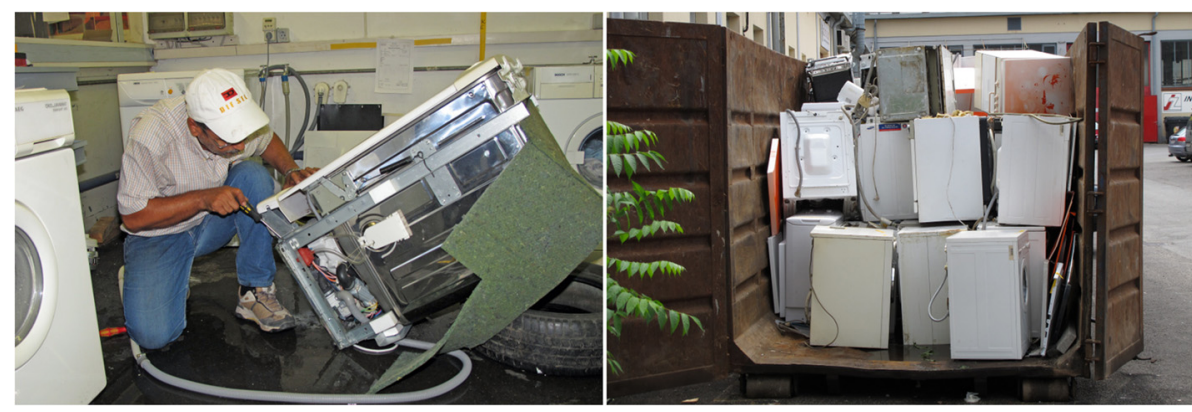

Fig. 7 Repair shop and recycling container (Source: R.U.S.Z)

impact of R.U.S.Z' activities' for details concerning R.U.S.Z' energy efficiency activities). Spare parts can be extracted from all white goods, independent from their classification (see Fig. 6). However, the best sources for spare parts are acquired items in a bad but still usable condition. Products with better qualities are preferably prepared for reuse due to their superior profitability. According to R.U.S.Z, several spare parts can be recovered from one item, e.g., in the case of washing machines, program selector switches, pumps, motors and so forth. Interestingly, the parts oftentimes are standardized, thus they can be used for several product types of a brand or even for reprocessing products of different brands. The cannibalization of designated used products needs an amount of work of about 20 minutes.

Besides the reprocessing of entire products, a special case is the recovery of washing machine motors: because of the large quantities of precious copper used for the production of these motors, investing 15 minutes of worktime in disassembling the motor pays of in any case, as the value of these recovered resources exceeds the spent effort. Thus, even broken washing machine motors are dismantled.

Next to the usage for reprocessing, spare parts are sold to do-it-yourselfers in rare cases. A further aspect concerns the repair service offered by R.U.S.Z: as customers prefer new spare parts, spare parts gathered from used items are hardly used for customer repairs. All remaining white goods are recycled in cooperation with a waste collection service provider (see Fig. 7).

\section{Error-proneness of the grading process}

Although the used products are classified in a grading process, it often turns out that the actual quality of a product was determined imprecisely. This is caused by the type of sorting process: as R.U.S.Z performs a visual inspection, the quality of the acquired used product can only be estimated. The actual quality is observed in the course of reprocessing, when the product is (partially) disassembled. Thus, the disposition decisions on reprocessing the items are made based on an erroneous grading process. This interesting observation is explored in Table 4, which presents a comparison of the grading decisions and the actual disposition decisions. Due to restricted capacity and resultant lags of time before processing, not for all of the received used products reprocessing is finalized. These items - for instance, items received shortly before end of year 2013 - are stocked and marked as 'No Final Decision.'

About $48 \%$ of used products classified as class 1 were sold, $18.5 \%$ were used for spare parts recovery, and around $6 \%$ were collected for recycling. Concerning the remaining 
items, no final disposition decision has been made. The proportion of products used for spare parts recovery or being recycled increases in the case of class 2/3-products, in particular since October 2012 when the classification strategy has changed. Although those used products were intended to be sold, large amounts of products were treated differently than the previous grading result suggested. Vice versa, caused by data inconsistencies, used items classified for spare parts recovery or - in exceptional cases - recycling were sold, and some products intended to be recycled functioned as spare part suppliers. Summing up, the actual quality of an item is not determined at the grading process but at its reprocessing. The grading process delivers an estimation of the product condition. However, the question why to conduct the grading process in consideration of the errorproneness of the grading process remains. Although this question can not be answered exhaustively in the course of this case study, an indication for a potential answer can be identified in the next Section 'Lead time analysis of reprocessing.'

\section{Lead time analysis of reprocessing}

R.U.S.Z is limited in terms of acquisition, testing/sorting, and reprocessing capacities, what may lead to consequences like the aforementioned process time lags or excessive inventories of used products/spare parts. The implications of limited capacity in the reverse logistics processes are explored with a lead time analysis. In this case study, the lead time is defined as the time between the arrival of a used product at R.U.S.Z' site until the completion of activities (reprocessing, spare parts recovery, collection for recycling), whereby a lead time of 0 means a completion at the same day.

In the years 2011, 2012, and 2013, 3,435 items were recorded in the business database. Out of this dataset, 48 records could not be used due to data inconsistency, and 387 items were not completed (no final decision). The items were split according to their actual use. Therefore, the analysis consists of lead times related to reprocessed items, used products for spare parts recovery, and items collected for recycling.

Table 5 shows some statistics concerning the data records used for the analysis of lead times at R.U.S.Z. The 3,000 data records show that many used products were collected for recycling, while around $21.93 \%$ were reprocessed. Both the median and the mean indicate that reprocessing was performed at the same time or faster than gathering spare parts. This can be explained by the superior prioritization of reprocessing with subsequent sales compared with spare parts recovery. Interestingly, the median of used products which were destined for recycling is zero, so a good portion of used white goods was sorted out immediately after the arrival at the R.U.S.Z-site. This fact implies a potential answer to the question regarding the value of an error-prone grading process (see Section 'Errorproneness of the grading process'). Used products which are apparently not reprocessable

Table 4 Grading decision vs. actual disposition decision (2011, 2012, 2013)

\begin{tabular}{|c|c|c|c|c|c|c|}
\hline \multicolumn{2}{|c|}{ Classification decision } & \multicolumn{5}{|c|}{ Actual disposition decision } \\
\hline Selection for reuse & Classification & Sales & Spare parts & Recycling & No final decision & Total \\
\hline \multirow[t]{3}{*}{ YES } & Class 1 & 287 & 110 & 35 & 162 & 594 \\
\hline & Class 2 & 131 & 108 & 63 & 94 & 396 \\
\hline & Class 3 & 267 & 247 & 209 & 131 & 854 \\
\hline \multirow[t]{2}{*}{ NO } & Spare parts & 2 & 432 & 94 & 0 & 528 \\
\hline & Recycling & 2 & 18 & 1,043 & 0 & 1,063 \\
\hline Total & & 689 & 915 & 1,444 & 387 & 3,435 \\
\hline
\end{tabular}


Table 5 Statistics concerning lead times

\begin{tabular}{llll}
\hline & Reprocessing & Spare parts & Recycling \\
\hline $\begin{array}{l}\text { Number of data records } \\
\text { Total }\end{array}$ & 658 & 907 & 1435 \\
$<90$ days & 585 & 763 & 1255 \\
Lead time (total dataset) & & & 0 \\
Minimum [days] & 0 & 0 & 0 \\
Median [days] & 8 & 8 & 32.84 \\
Mean [days] & 32.98 & 49.64 & 652 \\
Maximum [days] & 596 & 737 & 0 \\
Lead Time (<90 days) & & & 0 \\
Minimum [days] & 0 & 0 & 6.54 \\
Median [days] & 7 & 5 & 89 \\
Mean [days] & 14.56 & 14.33 & \\
Maximum [days] & 89 & 89 & \\
\hline
\end{tabular}

are eliminated before the actual reprocessing. Consequently, this saves costly space in the capacity-restricted goods inventory.

Exceptional, long-lasting cases may bias the analysis. Therefore, an analysis including all data records with lead times of less than 90 days (or around 3 months) is shown in the lower part of Table 5. It turns out that - in contrast to the result above - in this setting the median of lead time for reprocessing is significantly greater than the one for spare parts recovery, while the mean only slightly differs.

We provide more analyses regarding the distribution of the lead times in Fig. 8. On the left, the analyses contain lead time data over the whole period. According to the statistics in Table 5, a bigger part of used products is treated within a lead time less than 90 days. Thus, the figures on the right are limited to this period.

Independent from the actual reprocessing decision, a great portion of used products was reprocessed within 29 days. Concerning the data including lead times with less than 90 days, the analyses are related reprocessing, spare parts recovery, and recycling. While the decision for recycling was made instantaneously in the course of the grading process in nearly $80 \%$ of all cases, both reprocessing of items $(12.82 \%$ reprocessed within one day) and spare parts recovery (27.52 \% finished within one day) were subject to varying lead times.

In the following Table 6, the lead time analysis depending on the completion year of reprocessing is presented. Particularly interesting is the impact of the decision concerning the strategy change in 2012/2013 to apply a stricter classification procedure. Nevertheless, the lead time may also be influenced by the lower total acquisition quantity. However, the impact of this reduction of acquired goods can not be explored in detail with the available data.

Overall, the lead times with respect to reprocessing, spare parts recovery, and recycling decreased significantly in 2013. This is true for the scenarios including all available data as well as for the data where the lead time is less than 90 days and concerns both mean and median values. The lead time without exceptional cases (lead time $<90$ days), which is more appropriate for determining lead times of day-to-day business, shows that for spare parts recovery and recycling the mean is less than the half. Interestingly, the decreased lead time concerning recycling is contrary to the fact that the recycled quantity increased. 


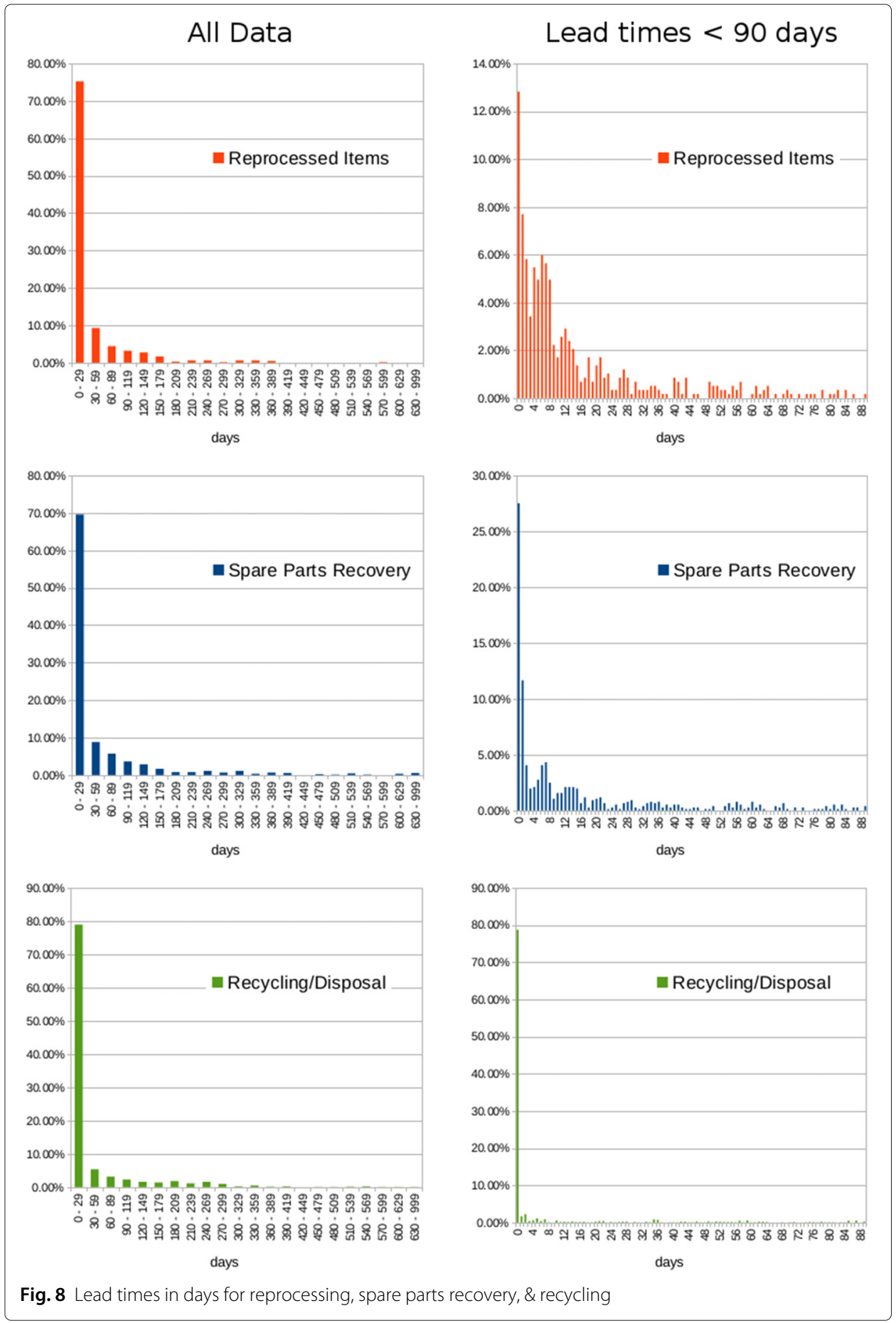

Additionally, also the average reprocessing lead time is considerably reduced by about $32 \%$, and the related median shows an improvement of even $50 \%$.

The key factors of the lead time reduction are the reduction of the total amount of acquired used goods and the focus on high-quality products. Naturally, the former directly reduces the total needed capacity for quality grading and reprocessing. Secondly, high-quality products in a good condition impact the needed reprocessing capacity: 
Table 6 Statistics concerning lead times per year

\begin{tabular}{|c|c|c|c|c|c|c|}
\hline & \multicolumn{3}{|c|}{ All data } & \multicolumn{3}{|c|}{ Lead time $<90$ days } \\
\hline & 2011 & 2012 & 2013 & 2011 & 2012 & 2013 \\
\hline \multicolumn{7}{|l|}{ Reprocessing } \\
\hline Quantity & 266 & 329 & 63 & 249 & 274 & 62 \\
\hline Min [days] & 0 & 0 & 0 & 0 & 0 & 0 \\
\hline Median [days] & 7.50 & 12 & 4 & 7 & 8 & 4 \\
\hline Mean [days] & 22.24 & 45.63 & 12.29 & 13.92 & 15.99 & 10.81 \\
\hline Max [days] & 241 & 596 & 104 & 82 & 89 & 69 \\
\hline \multicolumn{7}{|l|}{ Spare Parts } \\
\hline Quantity & 281 & 443 & 183 & 260 & 350 & 153 \\
\hline Min [days] & 0 & 0 & 0 & 0 & 0 & 0 \\
\hline Median [days] & 8 & 15 & 1 & 7 & 7 & 0 \\
\hline Mean [days] & 24.62 & 64.13 & 52.99 & 14.61 & 18.40 & 4.51 \\
\hline Max [days] & 313 & 663 & 737 & 87 & 89 & 84 \\
\hline \multicolumn{7}{|l|}{ Recycling } \\
\hline Quantity & 470 & 478 & 487 & 403 & 382 & 470 \\
\hline Min [days] & 0 & 0 & 0 & 0 & 0 & 0 \\
\hline Median [days] & 0 & 0 & 0 & 0 & 0 & 0 \\
\hline Mean [days] & 33.69 & 53.19 & 12.05 & 7.70 & 9.19 & 3.40 \\
\hline Max [days] & 338 & 652 & 490 & 85 & 87 & 89 \\
\hline
\end{tabular}

both the comparably good quality of the used products and easily accessible components (as described in Section 'Disposition process and reprocessing activities') reduce the reprocessing effort and consequently, the lead time.

\section{Markets \& demand}

According to R.U.S.Z, all of the remanufactured/refurbished products can be sold easily, as on average demand is greater than the number of finished items. Finished reprocessed goods are not always sold instantaneously but with time delays between the end of reprocessing and the actual sale, so the time when a product is finished may not necessarily coincide with the demand for a product. Besides the unknown demand time, also the demand size can not be determined exactly. The potential demand is great but not unconstrained: in detail, the number of socially disadvantaged households in Vienna with the need to exchange washing machines is projected at around 12,000 per year (about 50,000 in total Austria). Any potential conventional customers are added

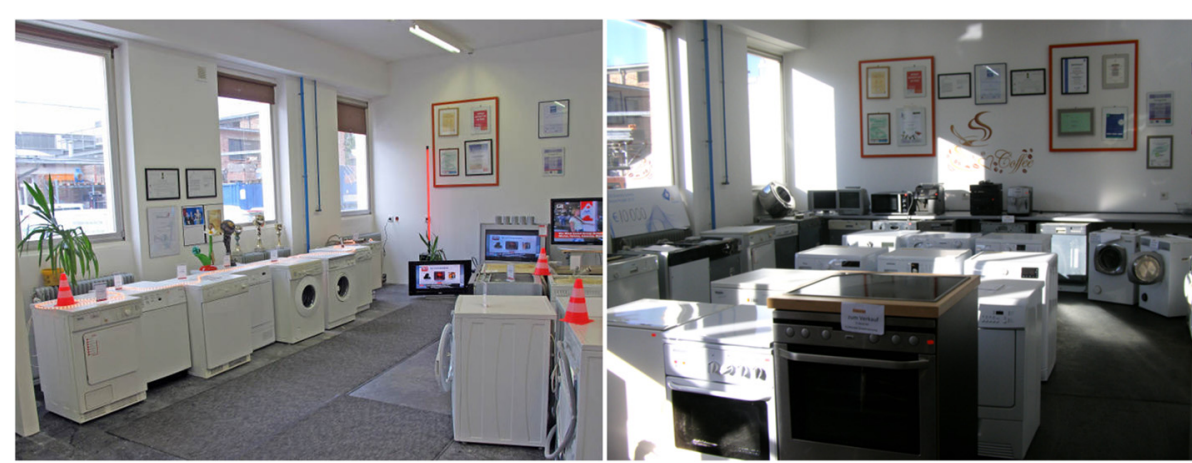

Fig. 9 Sales area of R.U.S.Z (Source: R.U.S.Z) 
to this number. As stated above, the supply with used products and the available production capacities of R.U.S.Z are limited. Consequently, the output of reprocessed white goods is restricted by the supply. Thus, the quantity demanded is far beyond R.U.S.Z capacities.

Since October 2012, the business strategy of R.U.S.Z has been adapted. Instead of focusing primarily on socially disadvantaged households, R.U.S.Z wants to change its image from a pure socially-concerned company toward an image which attracts additional target groups, e.g., ecologically and/or socially concerned higher income earners or students living in apartment-sharing communities. One of the main drivers of the business diversification was the overbalanced consideration of products classified as class 3 for social purposes. This resulted in small margin of profit or was - in single cases - even loss-generating due to the low sales price combined with a rather high reprocessing effort.

Regarding the sales prices of the reprocessed goods, the rule of thumb is to charge $1 / 3$ of the new product's price for a reprocessed item. In case of remanufactured products in an as-new shape and with a prestigious brand image, the sales price can be up to $1 / 2$ of the price of a new product. In detail, independent from the totally reprocessed volume the minimum sales price for a reprocessed washing machine must exceed $€ 280$ to ensure economical viability. The maximum price demanded for a remanufactured washing machine is about $€ 500$ for recent premium-quality branded goods. However, the final decision on the sales price is a matter of experience on the part of the R.U.S.Z sales team. According to R.U.S.Z, the popularity of reprocessed products does not solely depend on price: in the case that two technically similar products with differing ages and brands but identical expected durability are available, customers do not insist on the product with the favorable price. Customers also consider, e.g., brand awareness and age with respect to their buying decisions, so relatively new products of well-established brands are top sellers.

Following and extending legal requirements, R.U.S.Z offers a guarantee of one year for reprocessed and sold used products. The distinguishing feature of R.U.S.Z' guarantee compared to the implied warranty for sold second-life products is the voluntary waiver regarding the reversal of evidence while the duration of guarantee. Crucial for this is a strict compliance and documentation of checks and tests like the visual inspection before and both the functional and the safety test (specified in Austrian standard ÖVE/ÖNORM E 8701) after reprocessing in order to make sure meeting technical, legal, and consumers' requirements. A detailed overview of those requirements can be found in the Austrian guideline for reuse [5]. In the case of a legitimate claim, R.U.S.Z primarily tries to repair the broken part. However, in case the repair is not possible (e.g., due to overwhelming cost), the broken reprocessed product is exchanged with a comparable product free of charge. Interestingly, the guarantee was an additional driver for the change of strategy in autumn 2012: the original production materials used for items graded as class 2 or class 3 are of poor quality. This resulted in increased exchanges of products and repairs. So even in case the sales of items may have been profitable, the free after sales service for those broken refurbished products caused losses due to excessive expenditures of work and on material.

If an accident with a reprocessed product happens laws on product liability and product safety, respectively, are concerned. According to the Austrian guideline for reuse [5] and to the best of the authors' knowledge, there is no current jurisdiction regarding the liability 
of original manufacturers or reprocessing companies. This indicates that implemented safety mechanisms and quality checks work.

\section{Comparison of insights with other research results}

Overall, a comparison of the general activities concerning reverse logistics at R.U.S.Z with the existing literature shows that they are similar - and partially equivalent - to approaches known from and used in research (see, e.g., [13, 22, 23]).

A detailed comparison with other case studies provides further insights. The case of Electrolux is studied in [24] in order to determine the eco-efficiency of refurbishment and recycling, respectively. The results indicate that refurbishment is the preferred option. According to the conducted life cycle assessment (LCA), producing a new washing machine needs more than 30 times the energy of refurbishing a used one. In comparison with R.U.S.Z some similarities, but also some distinguishing factors can be found. First of all, Electrolux focuses on their own brands, while R.U.S.Z as an independent reprocessing company reprocesses various brands. Also the collection areas are different: Electrolux receives used goods from whole Sweden, while R.U.S.Z focuses on Vienna and surroundings, what impedes comparability with respect to supply quantities and transportation costs. At Electrolux the majority (about $83 \%$ ) of the used products is refurbished, while R.U.S.Z remanufactures/refurbishes about $22 \%$. Though, different from the information in this work R.U.S.Z earns money with recycled materials and does not have to pay fees for recycling. The reprocessing procedures are very similar: both Electrolux and R.U.S.Z prefer using parts harvested from formerly processed products as spare parts but do not resist to order new ones. In both companies spare parts recovery can also take place directly after the first visual inspection; items in a very bad condition are recycled. In order to ensure product quality, extensive testing procedures are integrated in both reprocessing systems. Regarding marketing, R.U.S.Z sells reprocessed products directly to end customers, while Electrolux delivers the refurbished products to retailers. Contrary to R.U.S.Z, refurbishment at Electrolux is profitable. Related to this, instead of great staff costs due to high amount of manual work as in the R.U.S.Z-case, Electrolux faces high overhead costs, e.g., for large storage areas. A minor commonality concerns the use of gained knowledge: Electrolux introduces it into new production, and R.U.S.Z uses it for analyzing durability and subsequent development of an ecodesign label for durable and easy-to-repair electronic and electrical products (ONR 192102).

In the work of Kissling et al. a typology for classifying reuse operating models for electrical and electronic equipment (EEE) is developed [25]. Following the results, R.U.S.Z as a not-for-profit and white goods-reprocessing company is closely related to "The Social Enterprise Model". Apart from the difference that the public funding rate is much lower at R.U.S.Z similarities can be identified:

- The major suppliers and customers are individual users.

- The reprocessing product mix at R.U.S.Z is in accord with the findings of Kissling et al., with a focus on washing machines.

- The costs for employees at R.U.S.Z are at the high end of the cost scale (40\%-70\%).

Generic success factors and barriers with respect to the reuse of EEE are identified in [26]. The authors identify the sourcing of used products as the most important barrier, particularly driven by the lack of legislation aiming at the support of reuse. Interestingly, 
in spite of the high level of manual effort labour costs (R.U.S.Z: more than $60 \%$ of all costs) were not considered as a big issue. Regarding sucess factors, the top three summarize a significant part of this study: 'Quality and reliability of products distributed for re-use', 'Control of product and process quality during preparation for re-use', and 'Access to high quality used equipment (local or import)'. All these success factors are directly related to key issues at R.U.S.Z: supply with used goods in sufficient condition and ensuring a high quality reprocessing flow with the objective of obtaining zero-defect saleable products.

O'Connell provides insights into Bryson Recycling (Northern Ireland) [27] and De Kringwinkel (Belgium) [28], two social enterprises acting in the field of reprocessing of white goods [29]. A major difference of De Kringwinkel from R.U.S.Z is the size of the company: it is not a small-scaled company but has more than 125 shops. Bryson employs skilled workers for the technical part of refurbishment and unskilled for collection and delivery, while De Kringwinkel focuses on training of unskilled workers in order to reintegrate them at the labour market. Supply with used products is critical as a minimum throughput is needed for reasons of viability: both companies face uncertain supply with used products at sufficient quality. The sources of supply are civic amenities and - very different from the R.U.S.Z-case - cooperating retailers in the case of Bryson Recycling; De Kringwinkel collects mainly at households, and additional quantities are obtained from reuse centers and municipalities. The reuse rate at De Kringwinkel is about the same as at R.U.S.Z with around $20 \%$, but the one at Bryson Recycling exceeds this value by far (about $72 \%$ ).

Further economic and ecological insights can be added considering work presented in $[10,30]$. The life cycle assessment-approach in [10] enables the exploration of the ecological and economical reasonableness of reusing used products with respect to the used products' ages. Taking the results into account, the strategy change of R.U.S.Z toward refurbishment of high-quality, energy-efficient used products is most likely beneficial in both dimensions. Duflou et al. list 17 companies related to disassembly of products, thereof two concerned with reusing of household appliances [30]. Both companies integrate similar reprocessing activities as R.U.S.Z, and their profits are at about break-even point. A linear programming model indicates that full disassembly of all used products is only profitable when wages are at a very low level. This analytical approach supports the findings that economic viability in the field of reprocessing of white goods is hard to achieve.

\section{Conclusions}

In this section we conclude the results of the presented case study. Based on the information provided above we identify research fields that may be explored and raise related questions.

\section{Operative planning}

In the case of R.U.S.Z, reusable and non-reusable used products are classified and sorted right after the acquisition, while the actual reprocessing activities are executed at future dates. This is caused by the following facts: first of all, acquisition, grading, and disposition/reprocessing are separated processes. Furthermore, the reprocessing activities per se are uncoupled from the acquisition. Additionally, they are subject to limitations of reprocessing capacity. For instance, one capacity bottleneck is the availability of trained 
staff, what results in a postponement of potential - economically reasonable - reprocessing related to the handing over of used products. Next to this reason, availability of used products as well as storage capacity limit the reverse logistics activities. Finally, the necessity to store graded used products and spare parts must be taken into account. Concerning the grading process, we observed discrepancies between the classification result of acquired used items and the actual reprocessing of these products; this is in line with both analytical and empirical scientific work (see, e.g., [31, 32]). Two main reasons were identified why the continuation of an error-prone grading process may be beneficial: first, the identification of obvious defects, which definitely prevent a profitable reprocessing, allows to recycle these goods instead of wasting storage capacity by storing. The second argument concerns the trade-off between grading and reprocessing: although the reprocessability of a graded used item is not ensured, the pre-selection increases the chance of not throwing away reprocessing capacity by trying to reprocess a non-reprocessable good. One of the cases described by the authors in [22] concerns CompCo, a non-profit company dealing with reprocessing computers. Interestingly, similar results regarding the reverse logistics processes can be found, which indicate the accuracy of this work in terms of external validity. For instance, both companies prevent a misusage as disposal company by charging a fee. While this is the case at CompCo when the donated computer can not be reprocessed, R.U.S.Z charges for the collection of used products. Another example concerns decision-making, which is in both companies based upon a visual inspection of the product's condition, the brand of the used product, and age.

An interesting aspect of R.U.S.Z' operations management is the interaction between reprocessing, supply with spare parts, and warranty. As mentioned above, warranty involves the requirement to provide after sales service in terms of the correct operation of the sold product. According to R.U.S.Z, guaranteeing a minimum additional utilization phase is necessary for customer confidence concerning reprocessed goods.

All of these activities are interrelated: the supply with spare parts is inevitable for maintenance of reprocessing operation. Nevertheless, an increased reprocessing rate cuts the availability of spare parts and vice versa. This is caused by both the limited capacity, which is used either for reprocessing or spare parts recovery, and the restricted number of available used products, which can be assigned to the options. Additionally, there are two opposing effects influencing future financial planning: on the one hand, short-term profit can be increased by rising reprocessing rates, involving greater risk to run out of spare parts in the future. On the other hand, reduced reprocessing results in lower shortterm profit, but makes possible sustainable business by increased spare parts availability. Obviously, this trade-off has great impact on the financial continuation of the company.

Some further goal conflicts appear concerning the relationship between reprocessing, spare parts recovery, and warranty: both reprocessing and after sales service - related to repairing of warranty claims - need spare parts. Consequently, spare parts recovery has to be balanced with respect to those both demands. Additionally, in some cases a sold product has to be replaced by another reprocessed item due to a warranty claim beyond repair. Finally, a relation between the classification of the acquired product and the chance of a warranty claim exists: for sold low quality reprocessed items (e.g., class 2 or class 3), the probability that an item requires repairing or replacement is increased. As explained above, this can be traced back to the worse material quality used for low-cost items by the OEM compared with products classified as class 1 . 
All in all, the case study gives rise to some questions concerning the operative planning at R.U.S.Z which can be modeled and explored:

- Assuming that a relation between acquisition effort and acquired quantity or quality of the products exists: Which acquisition effort should be taken? How can the stochastic returns be handled? Does an increased acquisition effort result in a raised return rate, or are there only substitutional effects between the offered collection service and used products returned by customers?

- Reprocessing of used products deviates from classification/grading, so grading errors may exist. How much effort should be spent for grading? How should the trade-off between increased effort for grading/less grading errors (and vice versa) be resolved?

- Which disposition options should be considered, especially in due consideration of different sales prices, reprocessing efforts, and capacity limitations?

- What is the optimal strategy for disposition of used products under given (uncertain) quality?

- How can the interrelations between reprocessing, spare parts recovery, and warranty be modeled, particularly over time? How can the optimal strategy including these three components be determined?

- How does the option of possible downward substitution affect the reverse processes (e.g., class 1-product used for spare parts recovery although demand may appear)?

\section{Business objectives: the effect of being an ecological, economical, or social company}

Another aspect concerning R.U.S.Z is the specific case of non-profit business. To the best of our knowledge, only a few articles of scientific work in the field of RL/CLSC consider NPOs. General aspects concerning, e.g., the development and design of a closed-loop supply chain or how to establish a framework to acquire used products are discussed by the authors in [33]. They study a collaboration between Nike and Throwplace.com; by means of this example, the authors show that a cooperation between an original equipment manufacturer and an NPO can be advantageous for both companies. As stated above, due to the fact that R.U.S.Z is a non-profit organization, the objectives partially differ from many profit-maximizing companies in the remanufacturing sector. However, to give consideration to the goals of R.U.S.Z, either a multi-objective-approach or an approach with maximizing ecological benefit under profitability/social constraints can be used.

The guiding research questions presented in Section 'Background' emphasize that the focus is on exploring R.U.S.Z under consideration of the fact that it acts as sustainable - and not solely profit-driven - company. Some aspects which differ from a profit-maximizing company were identified.

First of all, the focus of R.U.S.Z on environmental, economical, and social objectives results in suboptimal economic profitability. The reduced economic efficiency is caused by accepting additional risks (e.g., risk concerning potential reintegration by employing long-term unemployed people) or by preferring ecological/social rather than economical objectives (e.g., enabling of customer repairs by sales of spare parts despite cost for spare parts recovery exceeds the sales price).

The impact of the fact that products are sold with discount to socially disadvantaged people is twofold: obviously, the social benefit is that these people are provided with 
high-quality white goods instead of new low-quality products with short life cycles. Additionally, the high-quality products are more eco-friendly and efficient than the throwaway products, what results in an ecological benefit. However, this social responsibility involves not to insist on highest profitability of the sold products due to lower sales prices than possible.

Furthermore, the acquisition of used products depends on goodwill of potential donators, particularly in view of the additional effort/cost related to the pick-up service of R.U.S.Z or deliveries by customers.

An additional aspect concerns the staff: as mentioned above, R.U.S.Z employs longterm unemployed people what allows them to reintegrate in working life. The challenges of the employer-employee relationship in the case of R.U.S.Z exceed those of conventional employment, as the reintegration process often concerns both working life and social life. Therefore, support and assistance do not only concern working environment but also private life.

Two additional aspects concerning the ecological, economical, and social goals were identified:

- Under which conditions does the reprocessing strategy with ecological-economical-social goals differ from a profit-maximizing objective?

- How can the environmental impact of the different strategies be determined (new sales vs. sales of reprocessed products)?

\section{The relation between reprocessing and pricing in the market}

R.U.S.Z currently determines the sales prices of reprocessed products based upon a rule of thumb (1/3 to max. 1/2 of price of a new product). Assuming different qualities of the used products, one can ask how the optimal pricing strategy should look like, and furthermore, how the reprocessing activities interact with the market.

- How does the potential market structure influence the reprocessing decisions?

- How should R.U.S.Z price the reprocessed products?

\section{Competition vs. cooperation: why do big retailers not support the principle of providing returned used products for reprocessing/reuse?}

As addressed in Section 'Background', the case study also indicates that there is a lack of collaboration between manufacturers, retailers, and the reuse sector, although legislation aims at the preparation of returned items for reuse. Big retailers take back customers' used white goods when selling a new one. These retailers are not willing to cooperate with R.U.S.Z by providing the collected items, as they fear that the reprocessed white goods could cannibalize their own sales. According to R.U.S.Z, the superior market position and the resulting power in collecting used items is one of the main reasons for R.U.S.Z' low supply with used products.

Some examples dealing with competition in a manufacturing/remanufacturing context exist in scientific literature. An interesting approach is presented in [34]. Potential competition caused by a third-party remanufacturer threatens a manufacturer's profit. The authors analyze the conditions under which remanufacturing is profitable, and based upon the results entry-deterrent strategies are developed. Although the work aims at ensuring the manufacturer's monopolistic selling position, the presented framework 
is appropriate to cope with analytical modeling of holistic research questions involving all components of the triple bottom line. Overall, motivated by information of the R.U.S.Z-case, some questions are formulated:

- How does potential cooperation/competition influence the strategies of manufacturers/remanufacturers, big retailers, commercial collectors, and third-party reprocessing companies?

- Which consequences can be observed regarding ecological/social objectives, from a societal view or the view of ecologically or socially concerned reprocessors?

- How can policy-makers support desired development in the context of ecological/economical/social objectives? For example, in the case of either ambitious reuse rates or an integrative network of commercial collectors, waste collection service, recyclers, reprocessing companies: how do certain policies affect the stakeholders, and which consequences arise from that?

\section{Endnote}

${ }^{1}$ In this work, we consider acquisition and reprocessing of white goods. Apart from that, R.U.S.Z was one of the main initiators of Austrian mobile phone collection system 'Ö3-Wundertüte'. Used mobile phones can be donated by sending them to a collection center free of charge, where permanently unemployed persons sort the mobile phones and classify them into reusable and recyclable. Thereafter, the mobile phones are sold in an auction. Additionally, for each reusable or recyclable mobile phone, aid organizations receive a donation of $€ 3$ or $€ 0.5$, respectively. In 2012/2013, 457,000 mobile phones were donated [6].

Additionally, R.U.S.Z established a repair café [7] named 'Schraube14' in Vienna. In the course of this event, competent staff of R.U.S.Z assists to repair broken products by the owners. Besides providing the infrastructure for the repair café, this service is free of charge.

\section{Competing interests}

The authors declare that they have no competing interests.

\section{Authors' contributions}

Both authors contributed to the paper equally. MR was responsible for the introduction, GL conducted the interviews and analyzed the data. Remaining parts of the article were written in close collaboration between GL and MR. The authors read and approved the final manuscript.

\section{Acknowledgements}

This work has been supported by funds of the Oesterreichische Nationalbank (Anniversary Fund, project number: 14974).

The authors gratefully acknowledge this financial support.

Received: 23 February 2015 Accepted: 10 August 2015

Published online: 29 August 2015

References

1. Elektroaltgeräte Koordinierungsstelle: Tätigkeitsbericht (2013). http://www.eak-austria.at/presse/TB/ Taetigkeitsbericht_2013.pdf. Last access: Jul. 27th, 2015

2. Elektroaltgeräteverordnung, EAG-VO-Novelle 2014, BGBI II Nr. 193/2014 (2014)

3. Ecodesign. http://www.ecodesign.at/umsetzung/gesetze/weeepage/index.en.html. Last access: Jul. 27th, 2015

4. Final Report of Project 'Prozessoptimierung zur Sammlung und Behandlung von EAG mit dem Ziel der groesstmoeglichen Wertschoepfung' (OREG) funded by the Austrian Research Promotion Agency (FFG) under project number 841073 (available on request)

5. Spitzbart, M, Thaler, A, Stachura, M: Leitfaden für die Wiederverwendung von Elektroaltgeräten in Österreich. http://www.bmlfuw.gv.at/dms/Imat/greentec/abfall-ressourcen/abfallvermeidung/Wiederverw_EAG/ ReuseLeitfadenEAG_20Dez_2009/ReuseLeitfadenEAG_Nov_2009.pdf. Last access: Jul. 27th, 2015

6. Caritas. http://www.youngcaritas.at/aktionen/oe3-wundertuete/die-oe3-wundertuete. Last access: Jul. 27th, 2015 7. Repaircafé. http://repaircafe.org/about-repair-cafe. Last access: Jul. 27th, 2015

8. BC Centre for Social Enterprise: What is social enterprise? http://www.centreforsocialenterprise.com/what.html, Last access: Jul. 27th, 2015 
9. Cullen, JM, Allwood, JM: The Role of Washing Machines in Life Cycle Assessment Studies. J. Ind. Ecol. 13(1), 27-37 (2009). doi:10.1111/j.1530-9290.2009.00107.x

10. Devoldere, T, Willemss, B, Duflou, JR, Dewulf, W: The eco-efficiency of reuse centres critically explored - the washing machine case. Int. J. Sustain. Manuf. 1(3), 265-285 (2009)

11. O'Connell, MW, Hickey, SW, Fitzpatrick, C: Evaluating the sustainability potential of a white goods refurbishment program. Sustain. Sci. 8(4), 529-541 (2013)

12. Fleischmann, M, Van Nunen, JA, Gräve, B: Integrating closed-loop supply chains and spare-parts management at IBM. Interfaces. 33(6), 44-56 (2003)

13. Guide, VDR, Van Wassenhove, LN: Managing product returns for remanufacturing. Prod. Oper. Manag. 10(2), $142-155(2001)$

14. De Brito, MP, Dekker, R, Flapper, SDP: Reverse Logistics: A Review of Case Studies. In: Fleischmann, B, Klose, A (eds.) Distribution Logistics. Lecture Notes in Economics and Mathematical Systems, pp. 243-281. Springer, Berlin/Heidelberg, (2004)

15. Yin, RK: Case Study Research: Design and Methods. 4th edn. Sage Publications, Los Angeles (2009)

16. Meredith, J: Building operations management theory through case and field research. J. Oper. Manag. 16(4), 441-454 (1998)

17. Voss, C, Tsikriktsis, N, Frohlich, M: Case research in operations management. Int. J. Oper. Prod. Manag. 22(2), 195-219 (2002)

18. Fleischmann, M, Galbreth, MR, Tagaras, G: Product acquisition, grading, and disposition decisions. In: Ferguson, ME, Souza, GC (eds.) Closed Loop Supply Chains: New Developments to Improve the Sustainability of Business Practices, pp. 99-118. Taylor and Francis/CRC Press, Boca Raton, Florida, (2010)

19. Fellhuber, M: Weiße Ware: Top-Produkte für Küche und Depot. http://wirtschaftsblatt.at/archiv/1134416/index. Last access: Jul. 27th, 2015

20. R.U.S.Z: Personal Communication, Mar. 20th, 2014

21. Statistik Austria. http://www.statistik.at/web_de/statistiken/bevoelkerung/haushalte_familien_lebensformen/ haushalte/index.html. Last access: Jul. 27th, 2015

22. Errington, $\mathrm{M}$, Childe, $\mathrm{S}$ : A business process model of inspection in remanufacturing. J. Remanufacturing. 3(1), 1-22 (2013)

23. Inderfurth, K, de Kok, AG, Flapper, SDP: Product recovery in stochastic remanufacturing systems with multiple reuse options. Eur. J. Oper. Res. 133, 130-152 (2001)

24. Sundin, E, Tyskeng, S: Refurbish or recycle household appliances? an ecological and economic study of Electrolux in Sweden. In: Environmentally Conscious Design and Inverse Manufacturing, 2003. EcoDesign '03. 2003 3rd International Symposium On, pp. 348-355. IEEE, (2003). doi:10.1109/ECODIM.2003.1322690

25. Kissling, R, Fitzpatrick, C, Boeni, H, Luepschen, C, Andrew, S, Dickenson, J: Definition of generic re-use operating models for electrical and electronic equipment. Resour. Conserv. Recycl. 65, 85-99 (2012). doi:10.1016/j.resconrec.2012.04.003

26. Kissling, R, Coughlan, D, Fitzpatrick, C, Boeni, H, Luepschen, C, Andrew, S, Dickenson, J: Success factors and barriers in re-use of electrical and electronic equipment. Resour. Conserv. Recycl. 80, 21-31 (2013). doi:10.1016/j.resconrec.2013.07.009

27. Bryson Recycling. http://www.brysonrecycling.org/. Last access: Jul. 27th, 2015

28. De Kringwinkel. http://www.dekringwinkel.be. Last access: Jul. 27th, 2015

29. O'Connell, M: The Sustainability Potential of (W)EEE Re-use in Ireland; Evaluation, Implementation, Auto-Identification and the Internet of Things. PhD thesis, Department of Computer and Electronic Engineering, University of Limerick (2012)

30. Duflou, JR, Seliger, G, Kara, S, Umeda, Y, Ometto, A, Willems, B: Efficiency and feasibility of product disassembly: A case-based study. CIRP Ann. - Manuf. Technol. 57(2), 583-600 (2008). doi:10.1016/j.cirp.2008.09.009

31. Souza, GC, Ketzenberg, ME, Guide, VDR: Capacitated Remanufacturing with Service Level Constraints. Prod. Oper. Manag. 11(2), 231-248 (2002)

32. Tagaras, G, Zikopoulos, C: Optimal location and value of timely sorting of used items in a remanufacturing supply chain with multiple collection sites. Int. J. Prod. Econ. 115(2), 424-432 (2008). doi:10.1016/j.ijpe.2007.10.026

33. Kumar, $S$, Malegeant, $P$ : Strategic alliance in a closed-loop supply chain, a case of manufacturer and eco-non-profit organization. Technovation. 26(10), 1127-1135 (2006)

34. Ferguson, ME, Toktay, LB: The Effect of Competition on Recovery Strategies. Prod. Oper. Manag. 15(3), 351-368 (2006) 